\title{
Accurate measurements of ozone absorption cross-sections in the Hartley band
}

\author{
J. Viallon ${ }^{1}$, S. Lee ${ }^{2}$, P. Moussay ${ }^{1}$, K. Tworek ${ }^{3}$, M. Petersen ${ }^{4}$, and R. I. Wielgosz ${ }^{1}$ \\ ${ }^{1}$ Bureau International des Poids et Mesures (BIPM), Sèvres, France \\ ${ }^{2}$ Korea Research Institute of Standards and Science (KRISS), Daejeon, Republic of Korea \\ ${ }^{3}$ Central Office of Measures (GUM), Warsaw, Poland \\ ${ }^{4}$ University of Neuchâtel, Neuchâtel, Switzerland \\ Correspondence to: J. Viallon (jviallon@bipm.org)
}

Received: 13 May 2014 - Published in Atmos. Meas. Tech. Discuss.: 5 August 2014

Revised: 17 February 2015 - Accepted: 25 February 2015 - Published: 13 March 2015

\begin{abstract}
Ozone plays a crucial role in tropospheric chemistry, is the third largest contributor to greenhouse radiative forcing after carbon dioxide and methane and also a toxic air pollutant affecting human health and agriculture. Long-term measurements of tropospheric ozone have been performed globally for more than 30 years with UV photometers, all relying on the absorption of ozone at the $253.65 \mathrm{~nm}$ line of mercury. We have re-determined this cross-section and report a value of $11.27 \times 10^{-18} \mathrm{~cm}^{2}$ molecule ${ }^{-1}$ with an expanded relative uncertainty of $0.86 \%$ (coverage factor $k=2$ ). This is lower than the conventional value currently in use and measured by Hearn (1961) with a relative difference of $1.8 \%$, with the consequence that historically reported ozone concentrations should be increased by $1.8 \%$. In order to perform the new measurements of cross-sections with reduced uncertainties, a system was set up to generate pure ozone in the gas phase together with an optical system based on a UV laser with lines in the Hartley band, including accurate path length measurement of the absorption cell and a careful evaluation of possible impurities in the ozone sample by mass spectrometry and Fourier transform infrared spectroscopy. This resulted in new measurements of absolute values of ozone absorption cross-sections of $9.48 \times 10^{-18}, 10.44 \times 10^{-18}$ and $11.07 \times 10^{-18} \mathrm{~cm}^{2}$ molecule ${ }^{-1}$, with relative expanded uncertainties better than $0.7 \%$, for the wavelengths (in vacuum) of $244.06,248.32$, and $257.34 \mathrm{~nm}$ respectively. The cross-section at the $253.65 \mathrm{~nm}$ line of mercury was determined by comparisons using a Standard Reference Photometer equipped with a mercury lamp as the light source. The newly reported value should be used in the future to ob-
\end{abstract}

tain the most accurate measurements of ozone concentration, which are in closer agreement with non-UV-photometry based methods such as the gas phase titration of ozone with nitrogen monoxide.

\section{Introduction and aims}

The property of ozone to strongly absorb UV radiation, notably in the Hartley Band, and the relative ease of reproducing a mercury line at $253.65 \mathrm{~nm}$ (in air) has led to the value of the ozone absorption cross-section at this wavelength becoming particularly important for global ozone atmospheric monitoring. Efforts to improve its accuracy continue, as reviewed by Orphal (2002), because it directly impacts on all results from instruments based on UV absorption. This is the case in a majority of surface ozone measurements, for which an ISO method has been developed (ISO, 1996). The National Institute for Science and Technology (NIST) Standard Reference Photometer (SRP) operates on this principle, and also acts as the primary standard for numerous national and international ozone monitoring networks, such as the WMO Global Atmosphere Watch (GAW) Programme (Galbally et al., 2013; Klausen et al., 2003). Several replicas of this instrument are maintained by the International Bureau of Weights and Measures (BIPM), one of which is the reference for international comparisons of national ozone standards coordinated by the BIPM. The ozone absorption cross-section value at the $253.65 \mathrm{~nm}$ wavelength (Hearn, 1961) is the value used in the SRP, and was adopted as a conventional value 
during the Quadriennal Ozone Symposium in 1984 together with measurements by Bass and Paur for other wavelengths (Bass and Paur, 1984). Measurements of ozone absorption at other wavelengths have often been scaled to the value at $253.65 \mathrm{~nm}$, since they were performed in ozone in air mixtures, of which the ozone concentration is determined using its absorption at this wavelength. Broadband cross-section measurements with improved spectral resolution as well as an extended temperature range are required to match the conditions expected during atmospheric observations, such as those reported in a recent study (Serdyuchenko et al., 2014; Gorshelev et al., 2014) performed at IUP-Bremen. However, as highlighted by the authors, technical choices that are inherent to broadband laboratory measurements impose a limitation on achievable uncertainties to around (2-3)\% of the cross-section value.

Measurements performed at selected wavelengths and at room temperature can be performed with lower uncertainty than broadband measurements. This is mainly due to the use of a monochromatic light source, usually a mercury lamp, with well-defined wavelength(s). In addition, by limiting measurements to the strongest absorbing region of the spectrum, close to $255 \mathrm{~nm}$, all measurements can be performed with a single absorption cell, over a limited ozone pressure range and in a limited time to avoid ozone decay due to dissociation, as reported by Mauersberger et al. (1985, 1986, 1987). This group reported two values of the cross-section having a small relative standard uncertainty ( 0.5 and $0.7 \%)$, and with values smaller by 0.8 and $1.4 \%$ compared to the 1961 value reported by Hearn.

During the first international comparison of ozone standards for ground-level ozone conducted by the BIPM, 23 laboratories reported results based on UV absorption compared to two laboratories reporting ozone concentration measurements based on gas phase titration systems: the National Institute for Environmental Studies of Japan as described by Tanimoto et al. (2006) and the BIPM (Viallon et al., 2006a). Gas phase titration involves reacting ozone in air with nitrogen monoxide, and measuring either the loss of nitrogen monoxide or the gain of the reaction product, nitrogen dioxide, to deduce the ozone concentration in the sample. The (23) \% bias observed between the methods (gas phase titration reporting higher ozone concentrations) could be explained by a biased ozone absorption cross-section value, which represents the major uncertainty component in measurements based on UV photometry.

In 2007, the BIPM started a laboratory programme to perform new measurements of the ozone absorption crosssection with improved accuracy. Efforts focused on two major sources of uncertainty in the measurements: ozone purity and knowledge of the light path length. The BIPM first developed a laser ozone photometer, capable of measuring ozone concentrations in the same range as the SRP but with improved accuracy, as described in Petersen et al. (2012). This instrument was used to deduce new values of the ozone cross- section in the Hartley band, relative to the reference value obtained by Hearn at $253.65 \mathrm{~nm}$.

In the present study, absolute measurements of the ozone cross-section at the same wavelengths have been determined with the smallest uncertainties published to date. This required a cryogenic ozone generator to be developed, together with a method based on cycles of evaporation-condensation of ozone so as to better evaluate the purity of gaseous samples on which UV absorption measurements were performed. The measurement setup and associated process are presented in Sect. 2, followed by a discussion on the ozone purity in Sect. 3, which includes additional purity analyses by mass spectrometry and Fourier Transform Infrared spectroscopy (FTIR). The motivation for this work was to obtain a reduction in uncertainties and all possible sources of uncertainty are considered and evaluated in Sect. 4. Finally, values of the ozone cross-sections are presented in comparison with previous studies in Sect. 5 and a new value at the reference wavelength of $253.65 \mathrm{~nm}$ is calculated in Sect. 6. This work is in agreement with recent measurement results that indicate that the historical conventional cross-section value used for surface ozone measurements is biased too high, resulting in an underestimation of ozone concentrations, which can be corrected by use of the value published in this work.

\section{Measurement setup and process}

The setup, shown in Fig. 1, consists of four major parts: a silent discharge cryogenic ozone generator (CRYO), an absorption cell (AC), a pressure gauge (CDG) and a quadrupole mass spectrometer (RGA). The discharge cryogenic ozone generator is where ozone was generated from an electric discharge in pure oxygen (Linde, grade 6.0), using a method similar to that described by Janssen et al. (2011). The absorption cell is made of quartz and is where gaseous ozone at room temperature was introduced to allow absorption measurements to be performed with an intensity-stabilized UV laser beam. The pressure gauge is a capacitive diaphragm gauge with its heater turned off (1 Torr MKS 690A Baratron coupled with a MKS 670B signal conditioner) and is used to monitor the pressure of ozone samples at room temperature as well as the pressure of residual gases when ozone was condensed in the cryostat. The quadrupole mass spectrometer (RGA model MKS Vision $1000 \mathrm{C}$ ) is used to check the composition of residual gases. An additional pressure gauge (Pirani, Pfeiffer vacuum MPT100/PTR35-130) was used to monitor the oxygen pressure during ozone generation and the vacuum pressure during evacuation of gases with a turbo-molecular pump (TMP - Edwards STP 301C backed up with a primary pump Edwards XDS 10). Except for the quartz absorption cell, the measurement volume, i.e. the volume closed by valves V1, V2, V3 and V4, is made of 316 L stainless steel, including the four valves (VAT 26524-KE01BLV1) in which the gas is in contact with stainless steel 316 , 


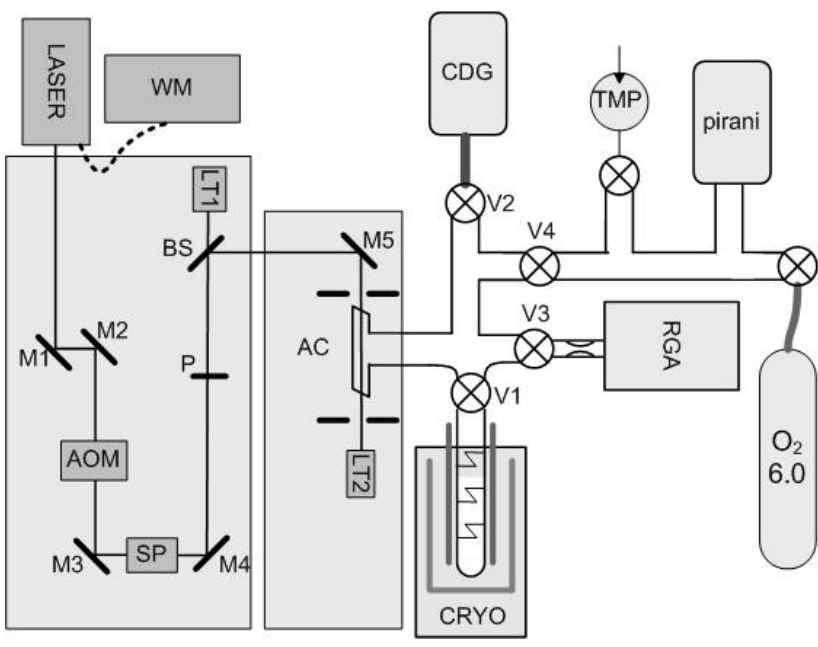

Figure 1. Measurement setup. AOM - Accousto-Optic Modulator; BS - Beam Splitter; CDG - Capacitive Diaphragm Gauge (Baratron); CRYO - cryogenic ozone generator; LT - Light Trap; M Mirror; RGA - Residual Gas Analyser (Quadrupole mass spectrometer); TMP - Turbo Molecular Pump; V - Valve; WM - Wavemeter.

except when they are open, allowing contact with the gate seals in Viton. Vacuum flanges were connected together and to the valves using aluminium seals, as this was found to minimize ozone losses compared to the original Viton seals, and avoid the formation of $\mathrm{CO}_{2}$ and $\mathrm{CO}$.

\subsection{Ozone production and storage}

Ozone was produced in a silent discharge cryogenic ozone generator especially designed for this purpose. The generation chamber is a long $(\sim 50 \mathrm{~cm})$ double-wall cylinder in quartz with a $3.9 \mathrm{~mm}$ gap width in which a glow discharge was created by applying a high voltage $(20 \mathrm{kV}, 20-70 \mathrm{kHz}$, typical current $1 \mathrm{~mA}$ ) to two foils maintained on the inside and outside of the cylinder walls. Valves V2 and V3 being closed, oxygen grade 6.0, the purity of which was further checked using the RGA, was introduced at a pressure of about 55 mbar into the generator, valve V4 was closed and the high voltage turned on to produce the silent discharge. About $90 \%$ of the $50 \mathrm{~cm}$ long cylinder was kept inside a variable-temperature cryostat filled with liquid nitrogen at its bottom (Janis VNF-100, with an operating temperature range of $(60-325) \mathrm{K}$, and temperature stability of $50 \mathrm{mK})$. With this design, it was found that the efficiency of ozone generation was at a maximum when the cryostat was kept between 88 and $92 \mathrm{~K}$, as measured with an additional temperature probe placed on the bottom of the ozone generator, inside the cryostat. After (2-3) h, a droplet of liquid ozone was observed on the bottom of the ozone generator, through the two quartz windows of the cryostat. The presence of liquid ozone meant that the silent discharge could then be turned off, and the cryostat temperature further reduced to below $78 \mathrm{~K}$, so as to trap all the ozone created inside the generator. Finally, the system was evacuated and the condensate was pumped for $20 \mathrm{~min}$ to remove oxygen and any other residual gases. The resulting amount of liquid ozone was sufficient to start absorption measurements using evaporation-condensation cycles as described in Sect. 2.2, starting with a first cycle of longer duration $(20 \mathrm{~min})$ and at the maximum ozone pressure of 1 mbar to passivate all surfaces.

\subsection{Ozone evaporation-condensation cycles}

Using the liquid ozone trapped in the bottom of the ozone generator, a series of evaporation-condensation cycles was performed so as to obtain about nine different ozone pressures in the gas cell to cover the range 0.2-1 mbar, whilst measuring the absorbance $A_{\mathrm{e}}$ at a fixed laser wavelength to determine the ozone cross-section. The process followed during those cycles was optimized during extensive testing to maximize the purity of the gaseous ozone samples released into the gas cell. The key parameters to monitor were the cryostat temperature $T_{\text {cryo }}$, the sample total pressure $P_{\mathrm{T}}$ measured with the Baratron, and the ozone partial pressure $P\left(\mathrm{O}_{3}\right)$ which at this point was used as an indicative real-time value determined using the following equation:

$$
P\left(\mathrm{O}_{3}\right)=\frac{A_{\mathrm{e}} R T_{\text {cell }}}{\sigma N_{\mathrm{A}} L_{\mathrm{opt}}},
$$

where $A_{\mathrm{e}}$ is the absorbance, $T_{\text {cell }}$ the gas cell temperature, $N_{\mathrm{A}}$ the Avogadro constant, $R$ the gas constant and $\sigma$ a value of the ozone cross-section chosen from the literature (the so-called BDM data set was used in this instance). These three parameters are displayed in Fig. 2 as recorded during the $15 \mathrm{~min}$ of a typical evaporation-condensation cycle. Each cycle started at time $t_{0}$ with valves V1 and V3 closed and V2 and V4 open to evacuate the gas cell and record the light intensity under vacuum $I_{0}$. Then $\mathrm{V} 2$ was closed to prevent ozone entering the Baratron pressure gauge where it could start to dissociate. In order to avoid rapid dissociation, the pressure gauge was maintained at room temperature rather than being heated to its normal operating temperature of $45^{\circ} \mathrm{C}$. Meanwhile, $\mathrm{V} 1$ was opened to allow pumping of the condensate for $5 \mathrm{~min}$ to remove any residual impurity. At time $t=5 \mathrm{~min}$, the cryostat target temperature was set to $105 \mathrm{~K}$. At time $t=6 \mathrm{~min}$, the valve V4 was closed to stop pumping, allowing the ozone pressure to increase with the cryostat temperature. When $P\left(\mathrm{O}_{3}\right)$ reached the target pressure (about $1 \mathrm{mbar}$ in the figure), V1 was closed and the cryostat target temperature set to $73 \mathrm{~K}$ (as indicated by the cryostat control system, or $78 \mathrm{~K}$ as measured with the temperature probe), which was reached in less than $1 \mathrm{~min}$. At that time V2 was opened to start recording the total pressure in the gas cell for approximately $30 \mathrm{~s}$. During post-treatment, the last values of the total pressure and of the light intensity recorded during this particular period were selected to further compute the cross-section. Then V1 was opened and all the 

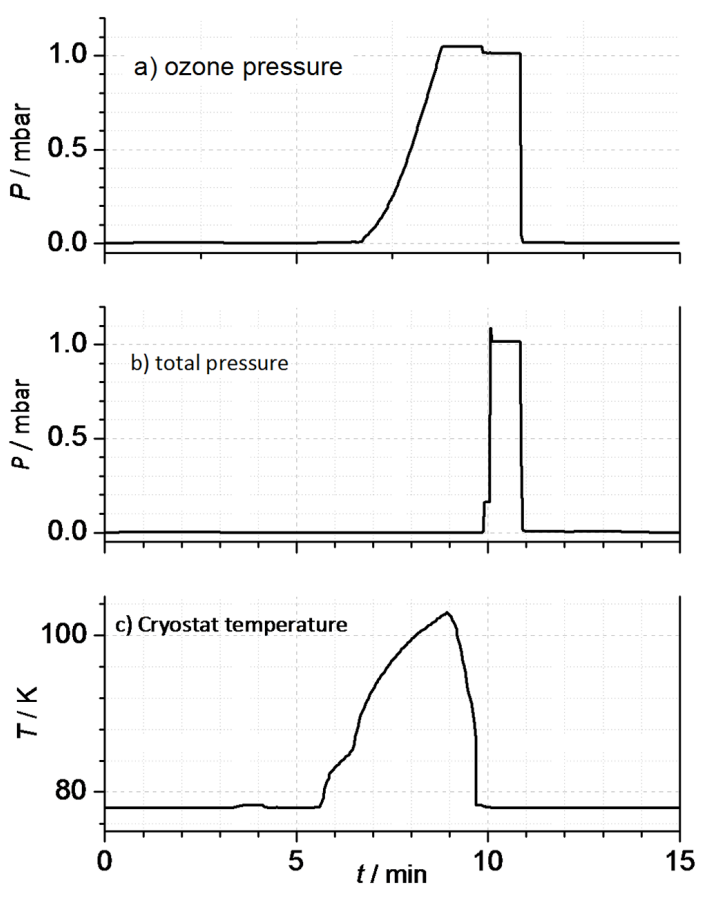

Figure 2. The measured values of key parameters during a typical evaporation-condensation cycle: (a) ozone partial pressure deduced from the absorption measurement $P\left(\mathrm{O}_{3}\right)$, (b) total pressure $P_{\mathrm{T}}$ measured with the Baratron gauge and (c) temperature $T_{\text {cryo }}$ inside the cryostat.

gaseous ozone was condensed again, lowering the total pressure to the residual pressure $P_{\text {res }}$, of the order of 0.01 mbar. When this pressure was stable, V1 was closed and V3 opened to allow the analysis of residual gases with the RGA for typically $1 \mathrm{~min}$. Finally the absorption cell was fully evacuated down to $10^{-7}$ mbar to start a new evaporation-condensation cycle.

\subsection{Optical setup for absorption measurements}

The optical setup was the same as described in Petersen et al. (2012) for the laser ozone photometer, except that the measurement cell was a $5 \mathrm{~cm}$ long absorption cell ( $\mathrm{AC}$ in Fig. 1) in quartz. The UV light was produced with an argonion laser doubled in frequency emitting light at either 244.06, 248.32 or $257.34 \mathrm{~nm}$ (wavelengths in vacuum).

Light traps (LT1 and LT2) composed of three windowless Hamamatsu S1337-1010-N photodiodes were used for detection of the UV beam. A spatial filter composed of a $75 \mathrm{~mm}$ focal length lens and a $20 \mu \mathrm{m}$ pinhole was used to give the beam a Gaussian shape. A $200 \mathrm{MHz}$ acousto-optic modulator (AOM) for UV-light between 244 and $266 \mathrm{~nm}$ was used to stabilize the power-level of the light on the LT1 light trap. The light power density was typically less than $10 \mu \mathrm{W} \mathrm{cm}{ }^{-2}$, and it was previously verified in Petersen et al. (2012) that there were no significant non-linear effects at this level.
The $5 \mathrm{~cm}$ long cell is made of quartz with fused silica windows tilted at $3^{\circ}$ to avoid multiple reflections of the beam inside the cell. The windows at each end of the cell are tilted in the same direction to maintain the same cell length. To ensure a consistent beam alignment through the cell, a special alignment tool in Teflon was machined and used to mount two diaphragms before and after the cell in fixed positions, so that their centres aligned with the cell horizontal axis. Both diaphragms were opened to less than $3 \mathrm{~mm}$ in diameter to constrain the laser beam. Then the alignment tool was removed to perform the measurement so as to avoid any scattering of light on its Teflon body. The light path length was measured before and after the ozone absorption measurement by interferometry, following a method described in the following section. To remove air turbulence and to significantly reduce temperature changes and background lighting the entire optical setup was enclosed in a thin aluminium casing and the cell in a thin black Plexiglas case.

\subsubsection{Absorption cell length measurements}

The method used for measuring the absorption cell length is based on counting interference fringes produced in a Michelson interferometer with the absorption cell placed in one of its arms, when evacuating the cell from air at ambient pressure to vacuum, due to the varying index of refraction in the arm with the cell. This method follows the process described in Castrillo et al. (2003) which accurately measures the light path length in a $\mathrm{CO}_{2}$ absorption cell. The interferometer was setup to have two parallel arms, with the light travelling through the room air in one arm and through the absorption cell in the other arm. A $5 \mathrm{~mW}$ He-Ne laser emitting light at $633.991 \mathrm{~nm}$ was used as the light source and its wavelength was accurately measured with the wavemeter. The ambient air pressure present in the absorption cell before pumping was measured with a barometer (Paroscientific model 740) traceable to the BIPM Mass Department. The vacuum pressure was measured with the Baratron. A dosing valve was used to limit the speed of the pressure drop during pumping. In a typical measurement, starting from an air pressure of $1018.84 \mathrm{hPa}$ and ending with less than $0.2 \mathrm{hPa}, 41.35$ fringes were counted, resulting in a path length of $48.32 \mathrm{~mm}$ with a standard uncertainty of $0.06 \mathrm{~mm}$ (at $65 \%$ degree of confidence or $1 \sigma$ ), according to the equation

$(n-1) L_{\mathrm{opt}}=\frac{F \lambda_{\mathrm{a}}}{2}$,

where $n$ is the index of refraction of air given by Edléns updated formula (Birch and Downs, 1993), $L_{\text {opt }}$ is the light path length in the absorption cell, $F$ is the number of fringes and $\lambda_{\mathrm{a}}$ is the laser wavelength in air. Calculations of the air refractive index included a correction to take into account the relative humidity in the laboratory air, controlled and measured at $50 \%$. This resulted in a correction of $0.1 \mathrm{~mm}$ on the path length. No correction for carbon dioxide was applied, as 
the laboratory average carbon dioxide amount fraction was $500 \mu \mathrm{mol} \mathrm{mol}^{-1}$, close enough to the $450 \mu \mathrm{mol} \mathrm{mol}^{-1}$ used in the Edléns formula so as to impact the path length by less than $0.004 \mathrm{~mm}$.

A series of 20 repeat measurements resulted in an average path length of $48.33 \mathrm{~mm}$, which was consistent with measurements of the cell length using a coordinate machine, which gave a value of $48.35 \mathrm{~mm}$.

\section{Ozone purity}

The purity of the ozone sample is of primary importance when measuring accurate ozone cross-sections. An analysis of the uncertainties shows that any impurity that would be above $1 \%$ in the sample should be measured and taken into account if the target uncertainty of the ozone cross-section is to be below $1 \%$. It is well known that, even when starting measurements with pure ozone samples, dissociation of ozone following collisions and interactions with surfaces will lead to the formation of oxygen. In addition, leaks within the system and reaction of ozone with contaminated surfaces could potentially lead to other trace contaminants being present. A comprehensive study of possible contaminants in ozone samples generated from oxygen by discharges followed by cryogenic distillation was performed by Janssen et al. (2011). As expected, oxygen was found to be the major impurity with a mole fraction of $1 \mathrm{mmol} \mathrm{mol}^{-1}$, followed by nitrous oxide at $0.3 \mathrm{mmol} \mathrm{mol}^{-1}$.

The setup adopted in this work was similar to that selected by Janssen, except that the chosen evaporation temperature for ozone was set to $105 \mathrm{~K}$. This has the advantage of ensuring that potential impurities such as carbon dioxide, nitrous oxide and water remain in the liquid phase. The main impurity that needs to be considered in this case is oxygen, and this is consistent with the observed variation in total pressure and the change in the ozone absorption signal expressed in ozone partial pressure using Eq. (1), during periods of ozone decomposition. The variation of the total pressure $\Delta P_{\mathrm{T}}$ measured while the Baratron gauge was in contact with the ozone sample was always compared with the variation of the ozone partial pressure $\triangle P\left(\mathrm{O}_{3}\right)$, determined from absorption measurements. Typical values of $\Delta P_{\mathrm{T}}$ were between $5 \times 10^{-4}$ and $1.4 \times 10^{-3}$ mbar and equal to half the value of $-\triangle P\left(\mathrm{O}_{3}\right)$, which was expected if ozone decomposes to oxygen and is well mixed. An example of the values obtained during a series of nine evaporation-condensation cycles is plotted in Fig. 3, where it can be seen that $\Delta P_{\mathrm{T}}=-\Delta P\left(\mathrm{O}_{3}\right) / 2$ within the measurement uncertainties, with any residual difference being always less than $1.5 \times 10^{-4}$ mbar. The presence of other minor impurities, notably $\mathrm{CO}_{2}$ and $\mathrm{CO}$, was evaluated and quantified using Fourier Transformed Infrared spectroscopy (FTIR) and Mass Spectrometry with a Residual Gas Analyser (RGA). Both measurements are described below, prior

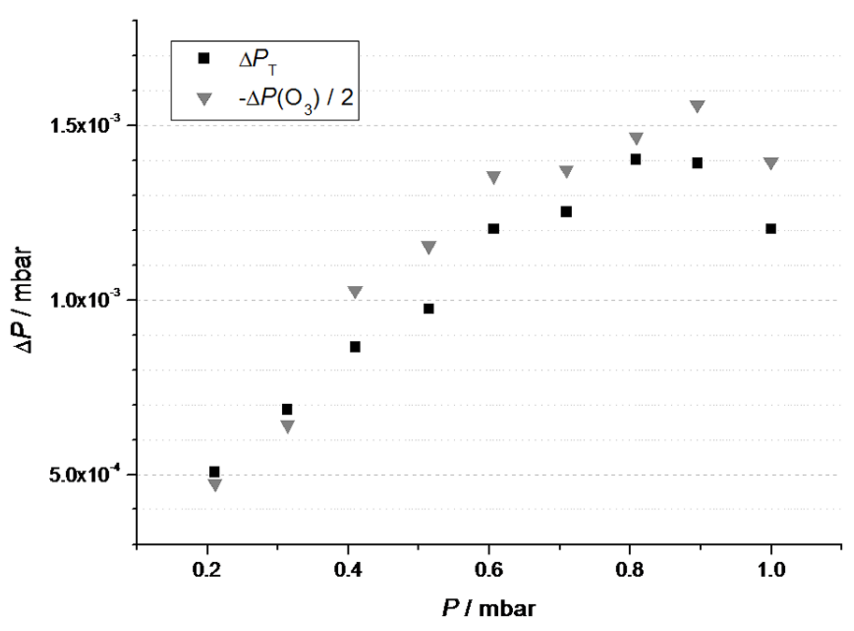

Figure 3. Increase of the total pressure $\Delta P_{\mathrm{T}}$ while ozone is in the absorption cell compared with half the decrease of the ozone partial pressure $\Delta P\left(\mathrm{O}_{3}\right)$ during the same time.

to the description of a model to take into account small losses of ozone observed during the measurements.

\subsection{Analysis of residual gases by mass spectrometry}

Mass spectrometry has already been used to analyse impurities in ozone samples by Anderson and Mauersberger (1981) and Mauersberger et al. (1985, 1986). It is however a complex measurement, as the ozone molecule is fragmented due to the impact of the electron beam required to produce ions, in addition to the possible dissociation due to non-polished metallic surfaces or even the presence of polymers within many commercially available mass spectrometers. The RGA used in the facility contains some non-metallic parts and not all of them could be replaced, resulting in rapid dissociation of ozone into molecular oxygen whenever the valve $\mathrm{V} 3$ to the RGA was opened, resulting in an inability to make accurate measurements of oxygen impurities in gaseous ozone. However, the RGA is a suitable instrument for residual gas analysis and could be meaningfully used to record mass spectra of the residual gases. For each evaporation-condensation cycle, one mass spectrum of the ozone vapour was recorded just before the cycle started, after having pumped on liquid ozone maintained at $78 \mathrm{~K}$. Then a second mass spectrum was recorded when the cycle was completed, when the ozone was again condensed at $78 \mathrm{~K}$. In general the intensity at mass 32 is partly due to the presence of molecular oxygen, and partly due to the fragmentation of ozone within the entrance of the RGA instrument where molecules entering collide with the electron beam. The difference $\Delta I_{32}$ between the signal at mass 32 recorded on the residual gases after condensation and on the ozone vapour can be attributed to molecular oxygen resulting from the dissociation of ozone during the evaporation cycle. A quantitative analysis was further performed, computing the oxygen pressure resulting from dissociation 


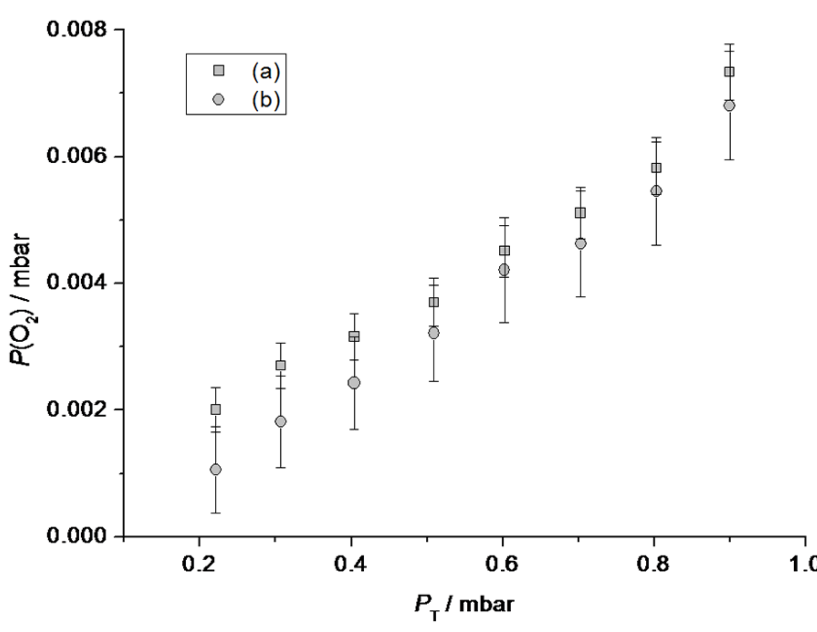

Figure 4. Oxygen pressure in the residual gas evaluated by pressure difference (a) and with the calibrated RGA (b).

during the evaporation from $\Delta I_{32}$. After each series of measurement, the signal intensity at mass $32 I_{32}$ was calibrated using pure oxygen at three different pressures covering the same range, typically between 0.001 and 0.01 mbar.

Applying the above process, the oxygen pressure deduced from the RGA should be comparable with the residual pressure $P_{\text {res }}$ corrected for the ozone vapour pressure $P_{\text {vap }}\left(\mathrm{O}_{3}\right)$ as measured by absorption. The values are shown in Fig. 4 against the sample pressure during the evaporation phase: (a) with squares for the oxygen pressure deduced from the difference $P_{\text {res }}-P_{\text {vap }}\left(\mathrm{O}_{3}\right)$, and (b) with circles for the oxygen pressure deduced from the difference in the RGA signal at mass 32, after calibration of the RGA with pure oxygen. Figure 4 shows that the two methods agree within their uncertainties, but with a systematic negative bias for the values deduced by analysis of mass 32 , indicating the possible presence of a non-condensable compound other than oxygen in the residuals. Mass spectra showed a small signal at $m / z=28$ that could be indicative of $\mathrm{CO}^{+}$ion. From a statistical analysis of all measurements an average partial pressure of $7 \times 10^{-4}$ mbar with a standard deviation (SD) of $3 \times 10^{-4}$ mbar was deduced for the contribution from nonoxygen non-condensable impurities.

\subsection{Analysis of samples by FTIR}

The above measurements with the RGA provide an analysis of the residual gases after condensation of the ozone sample. It is therefore not sensitive to condensable impurities that could result from the dissociation of ozone during the measurement phase, such as carbon dioxide, which was already observed in other similar measurements (Mauersberger et al., 1986). With this in mind, it was decided to perform an FTIR analysis of the gaseous ozone sample. A gas cell with a short path length of $10 \mathrm{~cm}$ was installed in a FTIR (ThermoScientific Nicolet Nexus) spectrometer con-

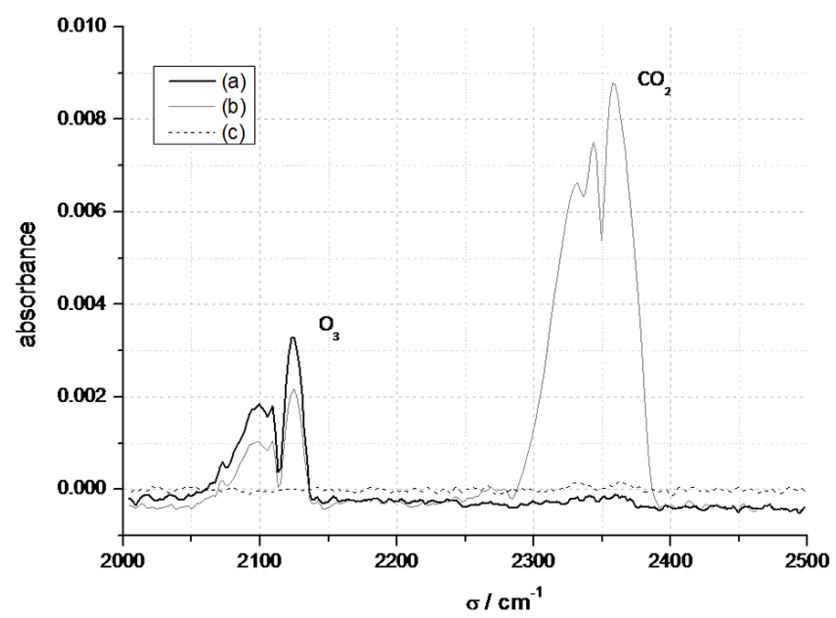

Figure 5. FTIR absorbance spectra recorded on a gaseous ozone sample at 1 mbar (a) and on the same sample after $12 \mathrm{~h}$ in the FTIR cell (b). An absorbance spectrum recorded with $10^{-3}$ mbar pure $\mathrm{CO}_{2}$ is plotted in (c) for comparison. Absorption peaks of ozone and carbon dioxide are indicated.

figured with a mercury cadmium telluride (MCT) high $\mathrm{D}^{*}$ liquid N2-cooled mid-infrared detector. The resolution had to be degraded to $4 \mathrm{~cm}^{-1}$ to compensate for the low signalto-noise ratio reached at these low pressures and to obtain a better signal in the carbon dioxide absorption band (2300$2400 \mathrm{~cm}^{-1}$ ). The FTIR gas cell was linked to the ozone generator using about one metre of stainless steel tubing due to the size of the spectrometer. A difficulty arising from this setup is the rapid reaction of ozone in contact with metallic surfaces and the O-rings in the connections to the FTIR cell, leading to a rapid increase of the carbon dioxide signal. The measurement process was improved by several hours of passivation at increased ozone pressure (about 9 mbar) and several cycles of filling both the UV absorption cell and the FTIR cell with ozone and then pumping down to $10^{-7}$ mbar. By doing so, the same process as used during the crosssection measurement to evaporate at least 1 mbar of ozone in the cell could be reproduced, resulting in FTIR spectra in which the carbon dioxide signal is lower than the calculated limit of detection. An example is displayed in Fig. 5. The FTIR spectra recorded with pure carbon dioxide at known pressure (measured with the Baratron) are shown demonstrating that pressures as low as $1 \mu \mathrm{bar}$ of $\mathrm{CO}_{2}$ could be detected with this experimental setup, with a calculated limit of detection of $3 \mu$ bar. The spectrum recorded on gaseous ozone at $1 \mathrm{mbar}$ is also shown, with a $\mathrm{CO}_{2}$ signal equivalent to a pressure of $1 \mu \mathrm{bar}$. This is a measure of the total $\mathrm{CO}_{2}$ formed by reactive surfaces not only in the absorption cell and in the cryostat of the apparatus but also in the FTIR cell and the gas lines and connection running to it. These connections expose the ozone to additional hydrocarbon surfaces that would not be found in the setup used for absorption measurements. However, even under these conditions, a pressure 
of only $1 \mu$ bar of $\mathrm{CO}_{2}$ was discernible. Therefore a value of $1 \mu$ bar of $\mathrm{CO}_{2}$ in the FTIR cannot be taken as the most likely pressure of $\mathrm{CO}_{2}$ present in the absorption system but rather the maximum possible, with the most likely being considerably smaller than this. The value of $\mathrm{CO}_{2}$ present has been taken as half of the limit value $(0.5 \mu \mathrm{bar})$, with a symmetrical rectangular distribution with limit values of zero and $1 \mu \mathrm{bar}$ used to calculate the measurement uncertainty. A significant $\mathrm{CO}_{2}$ signal can be recorded only after much longer exposure times, with the signal recorded after $12 \mathrm{~h}$ with the same sample in the system showing a measurable carbon dioxide peak, certainly due to reaction with ozone destructing surfaces in the spectrometer cell.

\subsection{Ozone losses model}

From the above analysis, it could be concluded that the oxygen pressure in the sample is simply the difference $P_{\text {res }}-P_{\text {vap }}$ as displayed in Fig. 4. However, as the measurement vessel of volume $V$ had to be open to the ozone generator vessel (of same volume) to condense ozone and measure the pressure above the residual gases, a model was introduced to further take into account the changes in volume and in temperature. It should be noted that this model introduces small pressure corrections of the order of $1 \mu \mathrm{bar}$.

During the first 4 min of a cycle, the cryostat temperature was increased to $105 \mathrm{~K}$, allowing ozone to evaporate at a pressure between 0.2 and 1 mbar. It was assumed that ozone decomposition during this phase could lead to formation of oxygen at a pressure $P_{1}\left(\mathrm{O}_{2}\right)$ in the volume $2 \mathrm{~V}$. When closing valve $\mathrm{V} 1$, both compartments - the cell and the cryostat - contained the same pressure of oxygen, but not at the same concentration due to the differences in temperature, the cell being at ambient temperature $T_{\text {cell }}$ and the cryostat volume at a mean temperature $T_{\mathrm{a}}=200.3 \mathrm{~K}$. Later on, during the measurement phase, some additional oxygen $\Delta P\left(\mathrm{O}_{2}\right)$ was created only in the cell volume $V$ due to the contact of ozone with the Baratron and the inside of the valve V2. This was monitored both with the Baratron and the ozone absorption in the cell. Meanwhile the cryostat volume temperature was further reduced to an average value $T_{\mathrm{b}}=186 \mathrm{~K}$. When opening again the valve $\mathrm{V} 1$ to condense ozone, the additional oxygen created in the cell was then mixed with the oxygen already present over the condensate, in a volume $2 \mathrm{~V}$ and at a new average temperature $T_{\mathrm{c}}$ (namely $2 \cdot T_{\mathrm{c}}^{-1}=T_{\text {cell }}^{-1}+T_{\mathrm{b}}^{-1}$ ). Expressing the equality between the total number of moles of oxygen over the condensate resulting from that process and as measured by the Baratron, the following can be written:

$$
\frac{\left(P_{\text {res }}-P_{\text {vap }}\right) 2 V}{T_{\mathrm{c}}}=\frac{P_{1}\left(\mathrm{O}_{2}\right) V}{T_{\text {cell }}}+\frac{\Delta P\left(\mathrm{O}_{2}\right) V}{T_{\text {cell }}}+\frac{P_{1}\left(\mathrm{O}_{2}\right) V}{T_{\mathrm{a}}},
$$

where on the left part of the equation, the ozone vapour pressure is subtracted from the residual gas pressure to obtain the oxygen pressure.
From this equation, the total oxygen pressure present in the cell during the absorption measurement, $P_{2}\left(\mathrm{O}_{2}\right)=P_{1}\left(\mathrm{O}_{2}\right)+$ $\triangle P\left(\mathrm{O}_{2}\right)$, can be deduced:

$\frac{P_{2}\left(\mathrm{O}_{2}\right)}{T_{\alpha}}=\frac{1}{T_{\beta}}\left(P_{\text {res }}-P_{\text {vap }}\right)+\frac{1}{T_{\mathrm{a}}} \Delta P\left(\mathrm{O}_{2}\right)$,

with the introduction of the temperatures $T_{\alpha}=$ $\left(\frac{1}{T_{\text {cell }}}+\frac{1}{T_{\mathrm{a}}}\right)^{-1}$ and $T_{\beta}=\left(\frac{1}{T_{\text {cell }}}+\frac{1}{T_{\mathrm{b}}}\right)^{-1}=T_{\mathrm{c}} / 2$.

The change in oxygen pressure was itself deduced from the change in total pressure, as ozone decomposed to oxygen only with the reaction $2 \mathrm{O}_{3} \rightarrow 3 \mathrm{O}_{2}$ :

$\Delta P\left(\mathrm{O}_{2}\right)=3 \Delta P_{\mathrm{T}}$,

so that the oxygen pressure during the measurement could be deduced from the residual gas pressure, the ozone vapour pressure, and the change in sample pressure:

$P_{2}\left(\mathrm{O}_{2}\right)=\frac{T_{\alpha}}{T_{\beta}}\left(P_{\text {res }}-P_{\text {vap }}\right)+3 \frac{T_{\alpha}}{T_{\mathrm{a}}} \Delta P_{\mathrm{T}}$.

During the nine series of measurements, the residual gas pressure, $P_{\text {res }}$, was typically between $5.0 \times 10^{-3}$ and $10 \times 10^{-3} \mathrm{mbar}$, increasing almost linearly with the sample pressure before condensation. The ozone vapour pressure measured by light absorption had a mean value of $3.47 \times 10^{-3}$ mbar with a SD of $0.5 \times 10^{-3}$ mbar. According to the measurements of Mauersberger et al. (1987), this value is representative of liquid ozone with a temperature of $78 \mathrm{~K}$, which is in agreement with the temperature probe measurement rather than the temperature provided by the cryostat control system. The same ozone vapour pressure value was found regardless of the laser wavelength used, giving more confidence in the robustness of this measurement. The oxygen pressure calculated using the above equation shows typical values between $2 \times 10^{-3}$ and $10^{-2}$ mbar.

Taking into account all impurities as detailed above, the final expression for the ozone mole fraction is

$x\left(\mathrm{O}_{3}\right)=1-\frac{P_{2}\left(\mathrm{O}_{2}\right)}{P_{\mathrm{T}}}-\frac{P\left(\mathrm{CO}_{2}\right)}{P_{\mathrm{T}}}-\frac{P(\mathrm{CO})}{P_{\mathrm{T}}}$

The ozone mole fraction in samples calculated for all measurement points is plotted in Fig. 6 versus the sample pressure before condensation. It shows minimum values of $0.981 \mathrm{~mol} \mathrm{~mol}^{-1}$, and maximum values of $0.996 \mathrm{~mol} \mathrm{~mol}^{-1}$, with uncertainties typically ranging from 0.001 to $0.005 \mathrm{~mol} \mathrm{~mol}^{-1}$, as explained in the following section.

\section{Measurement equation and uncertainties}

The ozone absorption cross-section can be deduced for a given ozone sample from the Beer-Lambert law:

$\sigma=\frac{R A_{\mathrm{e}} T_{\text {cell }}}{N_{\mathrm{A}} L_{\mathrm{opt}} x\left(\mathrm{O}_{3}\right) P_{\mathrm{T}}}=\frac{A_{\mathrm{e}}}{C L_{\mathrm{opt}}}$, 


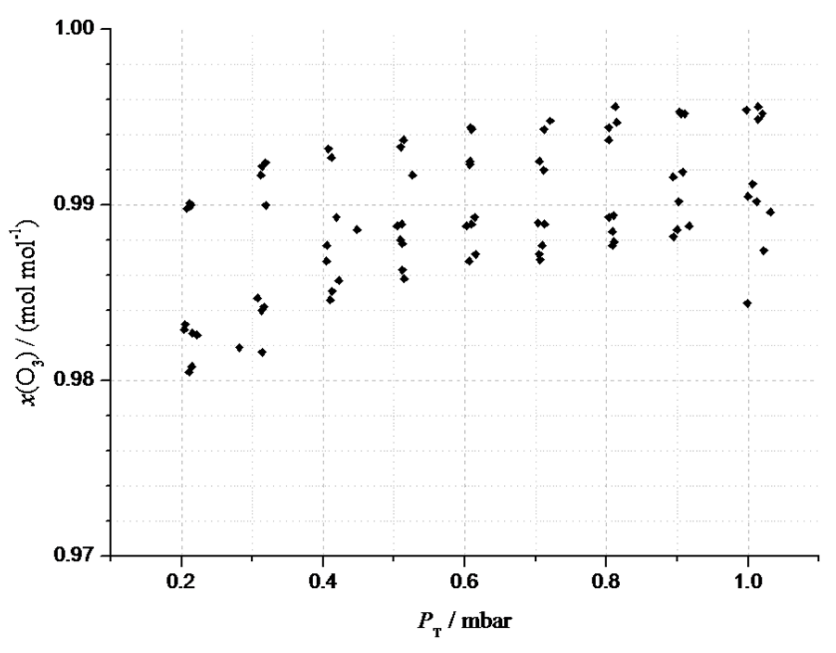

Figure 6. Ozone mole fractions $x\left(\mathrm{O}_{3}\right)$ in mol mol${ }^{-1}$ calculated for all measurement points, plotted versus the sample pressure $P_{\mathrm{T}}$ in mbar.

where $A_{\mathrm{e}}=-\ln \left(I / I_{0}\right)$ is the absorbance measured in realtime in the absorption cell, $P_{\mathrm{T}}$ the total pressure, $x\left(\mathrm{O}_{3}\right)$ is the ozone mole fraction in the sample calculated from Eq. (7), and $C=\frac{R T_{\text {cell }}}{N_{\mathrm{A}} x\left(\mathrm{O}_{3}\right) P_{\mathrm{T}}}$ is the ozone concentration in molecule $\mathrm{cm}^{-3}$.

In practice all parameters were recorded for each of the nine evaporation-condensation cycles performed during a series of measurements, each series was repeated three times on different days, and a linear regression of the absorbance $A_{\mathrm{e}}$ versus the product $C L_{\mathrm{opt}}$ was performed with those 27 measurement points to directly deduce the ozone cross-section associated with one laser wavelength from the slope of the regression line.

All the uncertainties in this section are calculated according to the Guide for Uncertainties in Measurements (BIPM et al., 1995).

\subsection{Pressure measurements}

The pressure inside the gas cell was measured with the CDG described in Sect. 2 with its heater turned off. Pressure measurements were effectively performed in two distinct ranges of the pressure gauge: from 0.2 to $1 \mathrm{mbar}$ when the gauge was in contact with the gaseous ozone sample, and from 0.005 to 0.015 mbar when it was employed to measure the pressure of the gas above liquid ozone, before or after an evaporationcondensation cycle. Furthermore, while the pressure above liquid ozone was a static measurement, the measurement performed on gaseous samples was a dynamic measurement due to the gauge being suddenly placed in contact with the gas, after being kept at about 0.001 mbar for several minutes, after which a rapid measurement was performed under a constantly increasing pressure due to the dissociation of ozone in oxygen. The pressure gauge was therefore calibrated in situ by comparison with another CDG (MKS model PR4000) itself regularly calibrated by the French National Metrology Institute (LNE, Laboratoire National de Métrologie et d'Essais), using two different approaches to match the measurements in these two ranges.

In the range $0.005-0.015$ mbar, a static calibration was performed, introducing nitrogen at ten fixed pressure points in a closed part of the setup, and recording measurements when the desired stability (SD lower than $10^{-5}$ mbar) was reached. Using this process the calibration uncertainty was dominant, leading to a standard uncertainty expressed in mbar of

$u_{\text {cal }}(P)=10^{-3} P+5 \times 10^{-5}$.

In the range $0.1-1$ mbar a dynamic calibration was performed in addition to the static calibration. During the dynamic calibration, nitrogen was introduced at an appropriate flow rate to obtain a constantly increasing pressure with a rate increase that matched the rate observed during measurements on ozone samples, typically of $5 \times 10^{-3} \mathrm{mbar} \mathrm{min}^{-1}$. Both dynamic and static calibrations agreed very well, resulting in the same calibration parameters. As the transfer standard PR4000 was calibrated in the low range $0.00-0.1$ mbar, a linear extrapolation was applied, followed by a correction as the sensor was used at room temperature instead of the recommended temperature of $45^{\circ} \mathrm{C}$, using the formula provided by Daudé et al. (2013). It was observed that this treatment produced results that agreed with the results of a calibration of the same sensor performed at $45^{\circ} \mathrm{C}$ one month previously by the LNE, confirming the validity of our in situ calibration process. Noting that the resolution and stability of the sensor are better than the calibration uncertainty, Eq. (9) was also used to calculate uncertainties associated with the ozone sample pressure measurements.

\subsection{Ozone purity}

The ozone purity was evaluated as the ozone mole fraction $x\left(\mathrm{O}_{3}\right)$ expressed in $\mathrm{mol} \mathrm{mol}^{-1}$ using Eq. (7). The sample pressure and residual pressure uncertainties are explained in the previous section. The FTIR measurements of carbon dioxide, considering $0.5 \times 10^{-3}$ mbar of carbon dioxide with flat uncertainty probability distribution between 0 and $1 \times 10^{-3} \mathrm{mbar}$, result in a standard uncertainty of $2.9 \times 10^{-4}$ mbar. The uncertainty associated with the noncondensable impurities detected by RGA was evaluated as the SD of the difference between oxygen pressures determined directly with the pressure sensor and indirectly with the RGA, resulting in a standard uncertainty of $3 \times$ $10^{-4}$ mbar. The uncertainty of the pressure sensor was not considered in that case as both values are highly correlated via its measurements, and also because the pressure sensor uncertainty is already taken into account in other terms of the uncertainty budget. 
The ozone vapour pressure, $P_{\text {vap }}$, was deduced from absorption measurements averaged over $20 \mathrm{~s}$, using literature values from Brion, Daumont and Malicet (also called BDM values; Brion et al., 1993, 1998; Malicet et al., 1995) for the ozone cross-section, with a standard uncertainty of $2 \%$. This uncertainty is sufficiently large to easily cover all probable values of the ozone cross-section, and makes the result independent of the actual literature value used among those published. The stability of the ozone vapour pressure measurement was taken into account by introducing the SD over $20 \mathrm{~s}$ of measurements, with a typical value of $8 \times 10^{-4} \mathrm{mbar}$. This component dominates the uncertainty on the oxygen pressure determined with Eq. (6). Combining this with the other impurities' uncertainties, as described in Eq. (7), results in an uncertainty on the ozone mole fraction, which is between $0.001 \mathrm{~mol} \mathrm{~mol}^{-1}$ at high sample pressure and $0.005 \mathrm{~mol} \mathrm{~mol}^{-1}$ for the lowest values of the sample pressure range.

\subsection{Ozone temperature}

The temperature in the absorption cell was measured by a thermo-resistor of $1 \mathrm{mK}$ resolution fixed to the exterior of the cell, close to one of its ends. The probe was calibrated on site by comparison with two reference temperature probes that had been regularly calibrated by the BIPM thermometry service, providing a calibration uncertainty of $0.018 \mathrm{~K}$. The cell was placed together with the photodiode within an enclosure in black Plexiglas to avoid stray light and also to stabilize the temperature, which was typically $295 \mathrm{~K}$ with less than $0.3 \mathrm{~K}$ variations during the measurement series. In order to measure temperature inhomogeneities in the cell, a separate series of measurements were performed, prior to the absorption measurements, with an additional probe installed inside the cell at its centre. Ozone evaporation-condensation cycles were performed so as to detect any temperature difference between the inside and outside of the cell, or between the centre and the cell end. A maximum difference of $0.045 \mathrm{~K}$ was measured, from which an uncertainty component $u_{\mathrm{dT}}=0.026 \mathrm{~K}$ was deduced. The probe inside the cell was then removed for absorption measurements to avoid ozone dissociation caused by the probe itself.

\subsection{Optical path length}

As explained in Sect. 2.3.1, the absorption cell path length was measured by interferometry. Uncertainties attached to all parameters required during this measurement were evaluated and are summarized in Table 1. The main uncertainty component was the number of fringes counted with the setup, which consisted of an electronic voltmeter to record the fringe signals from the photodiode on which interferences were created. The number of fringes was further counted with a program developed specifically for this purpose and doublechecked directly. Through this process it was possible to de-
Table 1. Uncertainty budget for the absorption cell light path length measurement.

\begin{tabular}{lcc}
\hline Parameter & Typical value & $\begin{array}{c}\text { Standard } \\
\text { uncertainty }\end{array}$ \\
\hline Number of fringes $F$ & 41.35 & 0.048 \\
Temperature $T$ & $22.72{ }^{\circ} \mathrm{C}$ & $0.034^{\circ} \mathrm{C}$ \\
Pressure $P_{\mathrm{a}}$ & $1018.84 \mathrm{hPa}$ & $0.945 \mathrm{~Pa}$ \\
Wavelength in air $\lambda_{\mathrm{a}}$ & $0.632827 \mu \mathrm{m}$ & $3.47 \times 10^{-6} \mu \mathrm{m}$ \\
Wavelength in vacuum $\lambda_{\mathrm{v}}$ & $0.632991 \mu \mathrm{m}$ & $0.29 \times 10^{-6} \mu \mathrm{m}$ \\
$L_{\mathrm{opt}}$ & $48.32 \mathrm{~mm}$ & $0.06 \mathrm{~mm}$ \\
\hline
\end{tabular}

termine where the fringe pattern started and ended with a precision of one-eighth of a fringe, resulting in a standard uncertainty of 0.048 fringes, assuming a rectangular distribution.

A series of 20 independent measurements were performed, resulting in an average cell length of $48.33 \mathrm{~mm}$ with a SD of $0.02 \mathrm{~mm}$. In addition, the possibility of a slight misalignment of the laser beam was taken into account. The beam alignment was performed using two diaphragms placed before and after the cell and kept in place with a $3 \mathrm{~mm}$ diameter aperture. Considering the $3^{\circ}$ angled windows and a cell length of $48.33 \mathrm{~mm}$, the shortest straight optical path hitting the diaphragm openings is calculated using the equation below with all length values (expressed in $\mathrm{mm}$ )

$L_{\min }=\sqrt{(3)^{2}+(48.33-3 \tan (3 \pi / 180))^{2}}=48.27 \mathrm{~mm}$

and the longest straight optical path is

$L_{\max }=\sqrt{(3)^{2}+(48.33+3 \tan (3 \pi / 180))^{2}}=48.58 \mathrm{~mm}$.

Assuming that any possible straight optical length in between these two lengths is equally possible, the standard uncertainty on the average cell length is (48.58$48.27) /(\sqrt{ } 12)=0.09 \mathrm{~mm}$, to be further combined with the uncertainty on the cell length as deduced from the interferometric measurements, resulting in a standard combined uncertainty of $0.11 \mathrm{~mm}$.

\subsection{Absorbance}

The electronic measurement system is described in Petersen et al. (2012). The intensity stabilization was ensured by the AOM, leading to a transmittance $I / I_{0}$ with a constant uncertainty of $1.2 \times 10^{-5}$, resulting in a standard uncertainty $u\left(A_{\mathrm{e}}\right)$ between $3.2 \times 10^{-5}$ and $6.3 \times 10^{-5}$ on the absorbance $A_{\mathrm{e}}$.

\subsection{Uncertainty budget}

Table 2 lists the sources of uncertainty in one typical measurement at a mean sample pressure of $0.5 \mathrm{mbar}$. The five uncertainty components associated with the experimental parameters $P_{\mathrm{T}}, x, T, L_{\mathrm{opt}}$ and $A_{\mathrm{e}}$ are valid for all three laser 
Table 2. Uncertainty budget for the ozone absorption cross-section measurement, indicated here for one typical measurement of the ozone absorption cross-section at a sample pressure of $0.51 \mathrm{mbar}$ and a laser wavelength of $244.06 \mathrm{~nm}$.

\begin{tabular}{lcr}
\hline Parameter & Typical value & $\begin{array}{r}\text { Relative } \\
\text { uncertainty }\end{array}$ \\
\hline Sample pressure $P_{\mathrm{T}}$ & $0.51 \mathrm{mbar}^{-1}$ & $1.00 \times 10^{-3}$ \\
Ozone fraction $x$ & $0.9863 \mathrm{~mol} \mathrm{~mol}^{-1}$ & $2.61 \times 10^{-3}$ \\
Temperature $T$ & $295.65 \mathrm{~K}$ & $8.79 \times 10^{-5}$ \\
Optical length $L_{\mathrm{opt}}$ & $48.33 \mathrm{~mm}$ & $2.28 \times 10^{-3}$ \\
Absorbance $A_{\mathrm{e}}$ & 0.564 & $6.63 \times 10^{-5}$ \\
\hline Cross-section systematic relative uncertainty & $3.60 \times 10^{-3}$ \\
\hline
\end{tabular}

wavelengths. The uncertainty is dominated by the absorption cell path length and the ozone fraction uncertainties, followed by the pressure measurements. The relative uncertainty resulting from these calculations has a dependency on the sample pressure, with a maximum value of $0.60 \%$ of the cross-section value at the lowest end of the pressure range $(0.2$ mbar) and a minimum value of $0.25 \%$ at the highest end of the range ( $1 \mathrm{mbar})$. Therefore the uncertainty associated with the product $C L_{\mathrm{opt}}$ was calculated for each data point and further used as a weight in the linear regression, as explained in the following section.

\section{Ozone absorption cross-section values at the three laser wavelengths}

Three series of measurements, each including nine points at different pressures covering the range $0.2-1$ mbar, were performed at each of the three laser wavelengths: 244.06, 248.32 and $257.34 \mathrm{~nm}$, constituting data sets of 27 points. Each measurement point was formed by the values $X=C L_{\mathrm{opt}}$ and $Y=$ $A_{\mathrm{e}}$ recorded during one ozone evaporation-condensation cycle. Each set of $27(X, Y)$ values was fitted using a linear regression model with uncertainties in both axes, following the generalized least-squares approach as described for example in Riu and Rius (1995). Calculations were performed with the software B_Least, detailed of which can be found in the ISO standard 6143 (ISO, 2001). One possible drawback of such a method is an underestimation of the slope uncertainty due to the averaging effect the regression when all points are considered independent. As such an assumption would not be valid in this case, the approach developed for ozone Standard Reference Photometers comparisons and detailed in Bremser et al. (2007) was introduced. An expression for the correlation between two $X$ values was derived from the part of the uncertainty that is common to both measurements, using the following equation:

$u\left(X_{i}, X_{j}\right)=9 \times 10^{-6} X_{i} X_{j}$.
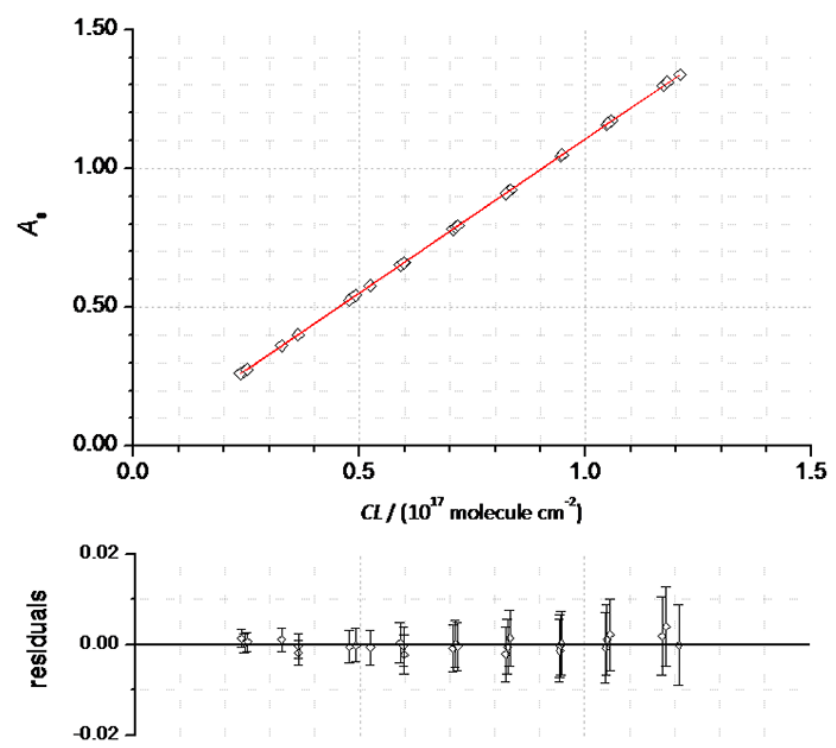

Figure 7. Example of the linear regression of measurements results recorded at the laser wavelength $257.337 \mathrm{~nm}$.

It should be emphasized that this represents a strong correlation between measurement points, which impacts the uncertainty of the slope of the regression but not the slope value itself, as explained in Bremser et al. (2007). One regression example is displayed in Fig. 7, which includes the data points and their uncertainties, the linear fit, and residuals from the fit with their uncertainties. All three regressions showed very similar characteristics, with no particular trend in the residuals and with residuals consistent with zero within their uncertainties. Intercepts ranged between $-1.2 \times 10^{-3}$ and $-1.9 \times 10^{-4}$ and were consistent with zero also within their uncertainties. The cross-section value from each series of measurements was directly obtained from the slope of the linear fit, as well as its standard uncertainty which ranged in value from $2.96 \times 10^{-20}$ to $3.46 \times 10^{-20} \mathrm{~cm}^{2}$ molecule ${ }^{-1}$. Those results are reported in Table 3 with the expanded uncertainty calculated with a coverage factor of 2 . A new value at the $253.65 \mathrm{~nm}$ line of mercury is also included in the same table, with the calculations performed to obtain it further explained in the next section.

To compare the results obtained here with previously published data, the data set from Bogumil et al. (2003) was chosen as the best representative historical conventional values used for ozone absorption cross-sections. This is because this group performed relative measurements using the absorption of ozone at $253.65 \mathrm{~nm}$ together with the crosssection measured by Hearn (1961) to deduce the concentrations in its measurements. The values published here, together with the values derived from measurements by Gorshelev et al. (2014), Brion et al. (1998) and Burrows et al. (1999) are compared as a difference from those of Bogumil. The Bogumil values here are only used for comparison 
Table 3. Values of the ozone absorption cross-section at the three wavelengths of the argon-ion laser and their expanded uncertainties (coverage factor $95 \%$ ).

\begin{tabular}{lll|cc}
\hline \multicolumn{2}{l}{ Laser wavelength $(\mathrm{nm})$} & & Ozone absorption cross-section & Expanded uncertainty \\
\cline { 1 - 2 } In vacuum & In air & \multirow{2}{*}{ Expanded uncertainty } & $\left(10^{-18} \mathrm{~cm}^{2}\right.$ molecule & -1 \\
\cline { 1 - 1 } 244.062 & 243.998 & 0.001 & 9.48 & 0.06 \\
248.323 & 248.249 & 0.001 & 10.44 & 0.07 \\
257.337 & 257.260 & 0.001 & 11.07 & 0.07 \\
253.73 & 253.65 & line of mercury & 11.27 & 0.097 \\
\hline
\end{tabular}

purposes, therefore they are considered as conventional with no uncertainty. The results are plotted in Fig. 8.

When analysing the data plotted in Fig. 8, it is important to bear in mind that Burrows et al. (1999) and Bogumil et al. (2003) both performed measurements scaled to the reference value of Hearn measured at $253.65 \mathrm{~nm}$. By comparison, Gorshelev et al. (2014) and Brion et al. (1998) implemented the same principle as the work reported in this paper, in which the ozone concentration is assessed independently by the measurement of the pressure of a pure sample. The two groups are clearly distinct on the plot.

Figure 8 also demonstrates that smaller uncertainties can be reached by the second method. This is however not exact, as the uncertainties associated with measurements relative to a reference are strongly dependent on the uncertainty on the reference, as already reported in Petersen et al. (2012). Therefore relative measurements would also benefit from using a reference with a reduced uncertainty compared to the Hearn value.

\section{Ozone absorption cross-section at the mercury lamp wavelength for surface ozone measurements}

The conventional reference value implemented for surface ozone measurements based on absorption at the $253.65 \mathrm{~nm}$ line of mercury is the value measured by Hearn in 1961, and is equal to $11.476 \times 10^{-18} \mathrm{~cm}^{2}$ molecule ${ }^{-1}$ (Hearn, 1961), with a relative expanded uncertainty of $2.12 \%$ (Viallon et al., 2006b). The methodology used to calculate absorption crosssections at different wavelengths as reported previously (Petersen et al., 2012) was used to calculate three values of the ozone absorption cross-section at the mercury wavelength used in the SRP. The three calculated values are $11.27 \times$ $10^{-18}, 11.30 \times 10^{-18}$ and $11.25 \times 10^{-18} \mathrm{~cm}^{2}$ molecule ${ }^{-1}$ using comparisons performed at the respective laser wavelengths of $244.06,248.32$ and $257.34 \mathrm{~nm}$, resulting in an average value of $11.27 \times 10^{-18} \mathrm{~cm}^{2}$ molecule ${ }^{-1}$ with a relative SD of the mean of $0.17 \%$. These results show a good agreement with the three series of measurements, which result in a negligible reproducibility uncertainty compared with our measurement uncertainty of $0.31 \%$. The uncertainty of the SRP without the ozone cross-section component is equal

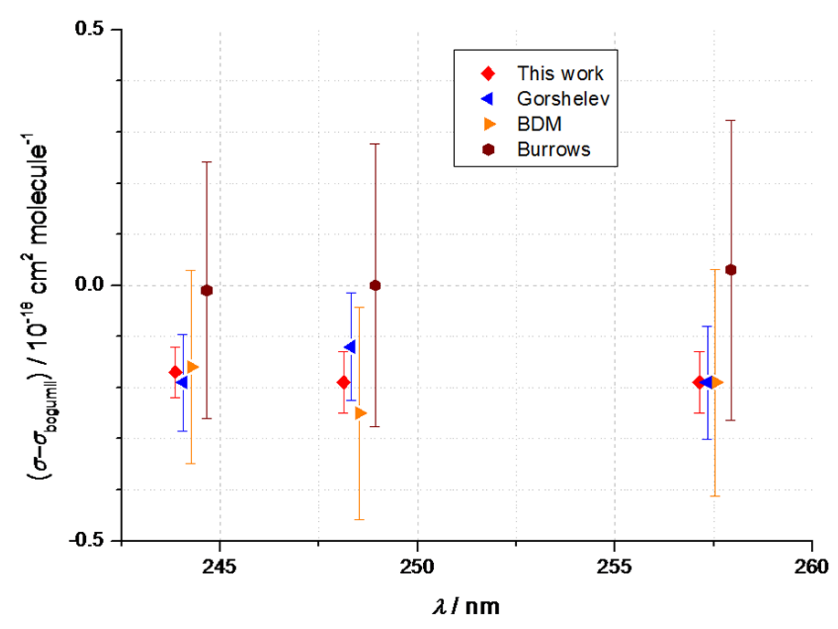

Figure 8. Comparison between the ozone absorption cross-section values measured by different groups at the three laser wavelengths examined in this study. Data were taken from the recent publication of Gorshelev et al. (2014) and the values measured by Bogumil et al. (2003) are subtracted from the other values. Wavelengths are plotted with a $0.2 \mathrm{~nm}$ shift from each other for clarity.

to $0.3 \%$, the main contributor being the path length uncertainty equal to $2.89 \times 10^{-3} x\left(\mathrm{O}_{3}\right)$, which takes into account reflections of light on the absorption cell windows and the non-collimated beam shape, as explained by Viallon et al. (2006b). Since that publication, the gas cells in SRPs maintained at the BIPM have been replaced with cells in quartz with their windows tilted by a $3^{\circ}$ angle, following the improvements recommended by Norris et al. (2013). Although there are indications that reflections of light are now avoided, this uncertainty component has not yet been re-evaluated. With the current SRP uncertainty budget, we obtain a relative standard uncertainty of $0.43 \%$ on the ozone cross-section value at $253.65 \mathrm{~nm}$.

The cross-section value at the mercury wavelength calculated above is $1.8 \%$ lower than the reference value of Hearn. If this new value was to be used in SRPs, it would mean an average increase of the measured ozone concentration of $1.8 \%$. This is consistent with the results obtained for gas phase titration in the international comparison CCQMP28 during which the bias between both methods was ob- 
served. The BIPM is working on reducing uncertainties for this method and this will be the subject of a future publication.

\section{Conclusion}

An experimental setup was developed to generate ozone samples of high purity and to carefully evaluate their purity to obtain an accurate basis for measurements of ozone absorption cross-sections with a laser in the Hartley band.

The use of an in-house cryogenic ozone generator together with a method based on cycles of evaporation and condensation of ozone led to gaseous samples with purity better than $98 \%$. Two analytical techniques, RGA and FTIR, were further implemented to confirm this value and to show that oxygen was the main impurity present in the samples, due to the reaction of ozone with surfaces.

This study reports absorption measurements performed for the first time in the Hartley band using a laser as the light source, allowing enhanced intensity stability together with an accurate knowledge of the absorption path length. Accurate values of the ozone cross-section at three wavelengths 244.06, 248.32 and $257.34 \mathrm{~nm}$ could be measured with a relative expanded uncertainty of $0.62 \%$. Compared to published data at the same wavelengths, the results obtained in this work are in good agreement with other recent values, and have the advantage of being reported with smaller uncertainties, and show the same level of bias with historical data sets.

Based on comparisons with a Standard Reference Photometer equipped with a mercury lamp as the light source, a mean value of $11.27 \times 10^{-18} \mathrm{~cm}^{2}$ molecule ${ }^{-1}$ was deduced for the ozone cross-section at the $253.65 \mathrm{~nm}$ line of mercury, with an expanded relative uncertainty of $0.86 \%$. This value is $1.8 \%$ lower than the value measured by Hearn and is in closer agreement with measurements based on the gas phase titration of ozone with nitrogen monoxide as will be presented in a future publication.

Acknowledgements. The authors would like to acknowledge the contributions of Edgar Flores (BIPM) in the FTIR analysis, Lennart Robertsson (BIPM) in the absorption cell path length measurement, and Richard Davis (BIPM) for advice on pressure measurements. All data used to deduce the ozone cross-sections were acquired experimentally and saved in ASCII format files. All files will be kept at the BIPM and can be communicated on demand. Data not acquired at the BIPM are published values of the ozone cross-section and in that case the sources are cited in this paper.

Edited by: Dr. M. Weber

\section{References}

Anderson, S. and Mauersberger, K.: Calibration of a mass spectrometer experiment for ozone, Rev. Sci. Instrumen., 52, 1025-1028, 1981.

Bass, A. M. and Paur, R. J.: The ultraviolet cross-section of ozone I: Measurements, Quadriennial Ozone Symposium, Halkidiki, Greece, 3-7 September 1984, 606-616, 1984.

BIPM, CEI, FICC, ISO, OIML, UICPA, and UIPPA: Guide to the Expression of Uncertainty in Measurement, International Organization for Standardization, Geneva, 101 pp., 1995.

Birch, K. P. and Downs, M. J.: An Updated Edlen Equation for the Refractive Index of Air, Metrologia, 30, 155-162, 1993.

Bogumil, K., Orphal, J., Homann, T., Voigt, S., Spietz, P., Fleischmann, O. C., Vogel, A., Hartmann, M., Kromminga, H., Bovensmann, H., Frerick, J., and Burrows, J. P.: Measurements of molecular absorption spectra with the SCIAMACHY preflight model: instrument characterization and reference data for atmospheric remote-sensing in the $230-2380 \mathrm{~nm}$ region, J. Photochem. Photobiol. A, 157, 167-184, 2003.

Bremser, W., Viallon, J., and Wielgosz, R. I.: Influence of correlation on the assessment of measurement result compatibility over a dynamic range, Metrologia, 44, 495-504, 2007.

Brion, J., Coquart, B., Daumont, D., Jenouvrier, A., Malicet, J., and Merienne, M. F.: High resolution laboratory absorption cross sections of ozone and nitrogen dioxide, Photo-oxid.: Precursors Prod., in: Proc. EUROTRAC Symposium 1992, 423-426, 1993.

Brion, J., Chakir, A., Charbonnier, J., Daumont, D., Parisse, C., and Malicet, J.: Absorption spectra measurements for the ozone molecule in the 350-830 nm region, J. Atmos. Chem., 30, 291299, 1998.

Burrows, J. P., Richter, A., Dehn, A., Deters, B., Himmelmann, S., Voigt, S., and Orphal, J.: Atmospheric remote-sensing reference data from GOME: 2. Temperature-depedent absorption crosssections of $\mathrm{O}_{3}$ in the 231-794 nm range, J. Quant. Spectrosc. Ra., 61, 509-517, 1999.

Castrillo, A., Gagliardi, G., Casa, G., and Gianfrani, L.: Combined interferometric and absorption-spectroscopic technique for determining molecular line strengths: applications to $\mathrm{CO}_{2}$, Phys. Rev. A, 67, 062503-062501, 2003.

Daudé, B., Elandaloussi, H., and Janssen, C.: On the gas dependence of thermal transpiration and a critical appraisal of correction methods for capacitive diaphragm gauges, Vacuum, 104, 7787, doi:10.1016/j.vacuum.2014.01.002, 2013.

Galbally, I. E., Schultz, M. G., Buchmann, B., Gilge, S., Guenther, F. R., Koide, H., Oltmans, S., Patrick, L., Sheel, H. E., Smit, H., Steinbacher, M., Steinbrecht, W., Tarasowa, O., Viallon, J., Voltz-Thomas, A., Weber, M., Wielgosz, R. I., and Zellweger, C.: Guidelines for Continuous Measurements of Ozone in the Troposphere, World Meteorological Organization, Geneva, 2013.

Gorshelev, V., Serdyuchenko, A., Weber, M., Chehade, W., and Burrows, J. P.: High spectral resolution ozone absorption crosssections - Part 1: Measurements, data analysis and comparison with previous measurements around $293 \mathrm{~K}$, Atmos. Meas. Tech., 7, 609-624, doi:10.5194/amt-7-609-2014, 2014.

Hearn, A. G.: The absorption of ozone in the ultra-violet and visible regions of the spectrum, P. Phys. Soc., 78, 932-940, 1961. 
ISO: Ambient Air - Determination of Ozone - Ultraviolet Photometric Method, International Organization for Standardization, 1996.

ISO: Gas Analysis - comparison methods for determining and checking the composition of gas mixtures, in International Organization for Standardization, 2001.

Janssen, C., Simone, D., and Guinet, M.: Preparation and accurate measurement of pure ozone, Rev. Sci. Instrum., 82, 034102, doi:10.1063/1.3557512, 2011.

Klausen, J., Zellweger, C., Buchmann, B., and Hofer, P.: Uncertainty and bias of surface ozone measurements at selected Global Atmosphere Watch sites, J. Geophys. Res.-Atmos., 108, 4622, doi:10.1029/2003JD003710, 2003.

Malicet, J., Daumont, D., Charbonnier, J., Parisse, C., Chakir, A., and Brion, J.: Ozone UV spectroscopy. II. Absorption crosssections and temperature dependence, J. Atmos. Chem., 21, 263273, 1995.

Mauersberger, K., Hanson, D., and Morton, J.: A new ozone standard: the vapor pressure of ozone at liquid argon temperatures, Geophys. Res. Lett., 12, 89-92, 1985.

Mauersberger, K., Barnes, J., Hanson, D., and Morton, J.: Measurement of the ozone absorption cross-section at the $253.7 \mathrm{~nm}$ mercury line, Geophys. Res. Lett., 13, 671-673, 1986.

Mauersberger, K., Hanson, D., Barnes, J., and Morton, J.: Ozone vapor pressure and absorption cross-section measurements: introduction of an ozone standard, J. Geophy. Res. D, 92, 84808482, 1987.

Norris, J. E., Choquette, S. J., Viallon, J., Moussay, P., Wielgosz, R., and Guenther, F. R.: Temperature measurement and optical path-length bias improvement modifications to National Institute of Standards and Technology ozone reference standards, J. Air Waste Manage., 63, 565-574, doi:10.1080/10962247.2013.773951, 2013.

Orphal, J.: A Critical Review of the Absorption Cross-Sections of $\mathrm{O}_{3}$ and $\mathrm{NO}_{2}$ in the 240-790 nm Region, ESA Technical Note MO-TN-ESA-GO-0302, European Space Agency, Noordwijk, 2002.
Petersen, M., Viallon, J., Moussay, P., and Wielgosz, R. I.: Relative measurements of ozone absorption cross-sections at three wavelengths in the Hartley band using a well-defined UV laser beam, J. Geophys. Res.-Atmos., 117, D05301, doi:10.1029/2011jd016374, 2012.

Riu, J. and Rius, F. X.: Univariate regression models with errors in both axes, J. Chemom., 9, 343-362, doi:10.1002/cem.1180090503, 1995.

Serdyuchenko, A., Gorshelev, V., Weber, M., Chehade, W., and Burrows, J. P.: High spectral resolution ozone absorption crosssections - Part 2: Temperature dependence, Atmos. Meas. Tech., 7, 625-636, doi:10.5194/amt-7-625-2014, 2014.

Tanimoto, H., Mukai, H., Hashimoto, S., and Norris, J. E.: Intercomparison of ultraviolet photometry and gas-phase titration techniques for ozone reference standards at ambient levels, J. Geophys. Res.-Atmos., 111, D16313, doi:10.1029/2005JD006983, 2006.

Viallon, J., Moussay, P., Esler, M., Wielgosz, R., Bremser, W., Novák, J., Vokoun, M., Botha, A., Janse Van Rensburg, M., Zellweger, C., Goldthorp, S., Borowiak, A., Lagler, F., Walden, J., Malgeri, E., Sassi, M. P., Morillo Gomez, P., Fernandez Patier, R., Galan Madruga, D., Woo, J.-C., Doo Kim, Y., Macé, T., Sutour, C., Surget, A., Niederhauser, B., Schwaller, D., Frigy, B., Györgyné Váraljai, I., Hashimoto, S., Mukai, H., Tanimoto, H., Ahleson, H. P., Egeløv, A., Ladegard, N., Marsteen, L. Tørnkvist, K., Guenther, F. R., Norris, J. E., Hafkenscheid, T. L., Van Rijn, M. M., Quincey, P., Sweeney, B., Langer, S., Magnusson, B., Bastian, J., Stummer, V., Fröhlich, M., Wolf, A., Konopelko, L. A., Kustikov, Y. A., and Rumyanstev, D. V.: Pilot study: International comparison CCQM-P28: ozone at ambient level, Metrologia, Tech. Suppl., 43, 08010, doi:10.1088/00261394/43/1A/08010, 2006a.

Viallon, J., Moussay, P., Norris, J. E., Guenther, F. R., and Wielgosz, R. I.: A study of systematic biases and measurement uncertainties in ozone mole fraction measurements with the NIST Standard Reference Photometer, Metrologia, 43, 441-450, $2006 b$. 